\title{
Jogos de Tabuleiro e Digitais para Estimular o Desenvolvimento do Raciocínio Lógico: Como Escolher?
}

\author{
Gilberto V. L. Júnior ${ }^{1}$, Thereza P. P. Padilha' ${ }^{1}$, Vinicius H. S. Gomes ${ }^{1}$ \\ ${ }^{1}$ Departamento de Ciências Exatas (DCX) - Universidade Federal da Paraíba (UFPB) \\ CEP - 58.297-000 - Rio Tinto - PB - Brasil \\ \{gilberto.vieira, thereza, vinicius.henrique\}@dce.ufpb.br
}

\begin{abstract}
Nowadays, it is known that there are a variety of games (digital or board games) for both educational and entertainment purposes. However, in the face of this diversity, choosing a certain game for the development of certain skills is an arduous process. Therefore, the objective of this article is to present an analysis of eight board games and their digital versions that support a series of benefits for the development of logical reasoning. Thus, as a result, a table is presented highlighting the main characteristics of these games to help teachers and also school managers in the choice of resources that aid learning.
\end{abstract}

Resumo. Atualmente, sabe-se que há uma variedade de jogos (digitais ou de tabuleiro) tanto para fins educacionais quanto para entretenimento. No entanto, diante desta diversidade, escolher um certo jogo para o desenvolvimento de determinadas habilidades é um processo árduo. Diante disso, o objetivo deste artigo é apresentar uma análise de oito jogos de tabuleiro e suas versões digitais que suportam uma série de benefícios para o desenvolvimento do raciocínio lógico. Assim, como resultado, é apresentada uma tabela destacando as principais características destes jogos para ajudar professores e, também, gestores escolares na escolha de recursos que auxiliem o aprendizado.

\section{Introdução}

O estudo do raciocínio lógico possibilita formar pessoas críticas com senso argumentativo, capazes de criar, interpretar, responder e explicar situações-problema. Aprender lógica desenvolve a organização e a sequência do pensamento a fim de inferir novos conhecimentos a partir dos existentes. Segundo Copi (1978), a lógica é o estudo de métodos e princípios para distinguir o raciocínio correto do incorreto. Para Piaget (1975), o conhecimento evolui progressivamente por meio de estruturas de raciocínio que substituem umas às outras através de estágios. Isto significa que a lógica e as formas de pensar de uma criança são completamente diferentes da lógica dos adultos.

De acordo com Sérates (1998), o raciocínio lógico é cheio de desafios e prepara o ser humano para o próximo milênio, que será caracterizado pelo ato de pensar. Vencerão aqueles que tiverem pensamento lógico, quem for criativo e inovador. Assim, nunca se precisou tanto de raciocínio lógico como nos dias atuais. Segundo Rauber et al. (2003), é comum encontrar alunos, inclusive universitários, com dificuldades para interpretar o que estão lendo, por não 
terem sido alfabetizados para entender o que está "por trás" daquilo que está escrito, ou seja, o real significado e o contexto. Isso, consequentemente, prejudicará toda a sua vida acadêmica e profissional. Embora muitas escolas trabalhem no desenvolvimento da autonomia dos estudantes, percebe-se ainda que os métodos são tradicionais e não oferecem muitas oportunidades para os alunos desenvolverem iniciativas ou tomarem suas próprias decisões. Uma alternativa para desenvolver habilidades de pensar em situações de causa-efeito, em futuras hipóteses e, também, em inferir novas informações é por meio do uso de jogos nas atividades educacionais. No entanto, como há uma diversidade de jogos digitais na Internet e também de tabuleiro que podem potencializar estas habilidades, torna-se bastante difícil escolher quais utilizar devido às suas características e que tipo de benefício pode trazer para os alunos e se ainda há alguma divergência entre as versões disponíveis.

Diante desta problemática, o objetivo principal deste trabalho é apresentar uma análise de oito jogos que podem ser encontrados facilmente tanto em nível físico (de tabuleiro) quanto na forma digital. Os jogos escolhidos foram: Batalha Naval, Cubo Mágico, Damas, Dominó, Trilha/Moinho, Resta Um, Sudoku e Xadrez devido serem os mais tradicionais. Estes jogos, no formato digital, podem ser acessados de forma gratuita por meio dos seguintes sites Racha Cuca1, Jogos 3602 e Mega Jogos3. O presente artigo encontra-se organizado da seguinte forma: na seção 2 é apresentada a importância do raciocínio lógico e suas contribuições; na seção 3 há a explanação dos oito jogos selecionados e suas características. Na seção 4 são apresentadas tabelas contendo a análise dos jogos e suas habilidades. Por fim, na seção 5, estão descritas as considerações finais.

\section{Raciocínio Lógico}

Segundo resultados da pesquisa realizada sobre a utilização de jogos educativos, foi observado que os professores pesquisados consideram seu uso vantajoso como estímulo para o processo de ensino e aprendizagem, favorecendo a motivação para a aprendizagem dos conteúdos escolares, promovendo o desenvolvimento do raciocínio lógico e a construção do conhecimento de maneira prazerosa e mais simples (Geller and Silveira, 1998).

Raciocínio lógico é um processo de estruturação/argumentação do pensamento que permite chegar a uma determinada conclusão, ou seja, requer consciência e capacidade de organização do pensamento. Existem diferentes tipos de raciocínio lógico como o indutivo, abdutivo e dedutivo, estes se diferenciam no modo como ocorre a estrutura do pensamento. $\mathrm{O}$ raciocínio indutivo parte do que é específico para a generalização, está atrelado à experiências empíricas, ou seja, ao pensamento intuitivo. Não contribuindo com novos conhecimentos, apenas tentando buscar uma melhor explicação, isto é, uma validação a conhecimentos já existentes. No raciocínio abdutivo é pouco semelhante ao indutivo, mas as conclusões apresentadas são baseadas em probabilidades, ou seja, na mais provável explicação para determinada premissa, considerada o único raciocínio de aquisição de conhecimento. $\mathrm{O}$ raciocínio dedutivo é o mais trabalhado porque busca realizar inferências, começando com proposições iniciais, alcançando conclusões intermediárias até culminar em uma conclusão.

O estudo da argumentação é extremamente importante, uma vez que argumentar é uma das facetas do raciocínio humano, assim como o provar e o calcular. Na literatura, é possível encontrar diversos trabalhos que relatam que o estudo da argumentação em crianças é tardio e, diante disso, cada vez mais iniciativas estão surgindo a fim de desenvolver habilidades lógicas 
para este público, que se encontra em constante aprendizado (Banks-Leite, 1996).

\section{Jogos Selecionados}

Os jogos digitais são uma aposta atraente para os usuários, visto que, nessa extensão tecnológica, as pessoas passaram a utilizar o celular para fazer tudo, inclusive jogar e aprender. Nesse processo de ascensão da tecnologia, os jogos clássicos como Damas, Xadrez e Trilha/Moinho passaram a ser virtualizados, sendo possível ser utilizados no próprio celular, substituindo a recreação tateável dos jogos tradicionais. Segundo Gros (2003), o jogo digital é uma das principais maneiras de se introduzir ao mundo da tecnologia, pois geralmente o videogame é o primeiro contato que uma criança ou jovem tem com equipamentos eletrônicos. Os jogos digitais podem ser explicitados por definição como ambiente aliciante e interativo que despertam a atenção dos jogadores ao oferecer desafios que exigem níveis graduais de estratégias e habilidades (Balasubramanian and Wilson, 2006).

Inclusive, há diversos estudos, conforme pode ser encontrado em (dos Santos et al. 2014, Oliveira et al. 2015 e Santos et al. 2013), a respeito de virtualização de jogos que estão sendo discutidos na intenção de criar versões digitais para jogos educativos tradicionais, prezando os aspectos pedagógicos, didáticos e psicológicos. Dentre as vantagens para esta virtualização, destacam-se a possibilidade de alcançar um maior número de pessoas, sendo possível usar por meio de tablets, celulares ou meios eletrônicos, dispositivos estes, usados frequentemente por crianças e adultos, a fim de jogar de forma gratuita encontrando-se disponíveis em vários sites na Internet.

No entanto, no caminho inverso ao mundo digital, em que majoritariamente as pessoas imergem seu tempo em dispositivos com acesso à internet, o mercado de jogos de tabuleiro vem se destacando no Brasil. De acordo com os dados estatísticos anuais divulgados pela Associação Brasileira dos Fabricantes de Brinquedos (ABRINQ)4, observa-se que, nos últimos anos, os jogos da linha tabuleiro (cartas, figuras e memória) têm superado as vendas de jogos digitais. Isso provavelmente tem se dado pelo fato que os jogos de tabuleiro proporcionam uma maior interação social de forma presencial, algo que havia sido perdido com os jogos digitais.

Os jogos têm sido utilizados em diversos aspectos, não somente aos associados a diversão e distração, todavia como jogos pedagógicos que têm como objetivos ampliar a concentração e o raciocínio lógico, estimular a criatividade, conduzir à construção do conhecimento e à aprendizagem. A seguir, é apresentada uma breve descrição do propósito/objetivo de cada um dos jogos selecionados.

- Batalha Naval (BN): identificar e afundar as embarcações (navios, submarinos) do adversário.

- Cubo Mágico (CM): organizar cada lado do cubo de uma única cor.

- Damas (DAM): capturar ou bloquear as peças do adversário.

- Dominó (DOM): colocar todas as peças na mesa antes do adversário.

- Resta Um (RU): deixar o menor número de pinos no tabuleiro, preferencialmente 1.

- Sudoku (SUD): encontrar os valores corretos para cada célula não preenchida.

- Trilha/Moinho (T/M): remover as peças do adversário até que restem no máximo 2.

- Xadrez (XAD): promover o "xeque-mate" no rei adversário. 


\section{Resultados da Análise dos Jogos}

Para este trabalho, o maior desafio foi, justamente, identificar se ambas versões dos jogos selecionados impulsionam o desenvolvimento das mesmas habilidades. Assim, inicialmente, foi analisado cada um destes jogos na sua versão de tabuleiro. As suas principais características e habilidades trabalhadas podem ser vistas nas Tabelas 1 e 2 , respectivamente. As colunas da Tabela 1 destacam as características básicas dos jogos: número de jogadores, faixa etária indicada para compreender o objetivo do jogo, complexidade para alcançar o objetivo, nível estratégico, tempo médio de uma partida (em minutos) e preço médio (mínimo-máximo encontrado em 3 sites clássicos de compras online).

Com o fito de definir os níveis de complexidade e estratégia, foi feita avaliação de acordo com as habilidades trabalhadas e o tempo de partida de cada jogo. Considerando todos os jogos, eles desenvolvem uma habilidade comum, a de estratégia. Após a identificação das habilidades, o passo seguinte foi testar, conjecturar em qual nível mais se aproxima e classificálos em baixo, médio e alto. A classificação definida está informada na Tabela abaixo, sendo que ainda não foi examinada por um grupo de usuários, tornando assim, atividades futuras.

Tabela 1. Características básicas dos jogos.

\begin{tabular}{|c|c|c|c|c|c|c|}
\hline Jogos & $\begin{array}{c}\mathbf{N}^{\mathbf{0}} \text { de } \\
\text { Jogadores }\end{array}$ & $\begin{array}{c}\text { Faixa } \\
\text { Etária }\end{array}$ & $\begin{array}{c}\text { Comple- } \\
\text { xidade }\end{array}$ & $\begin{array}{c}\text { Nível } \\
\text { Estratégico }\end{array}$ & Tempo & $\begin{array}{c}\text { Preço Médio } \\
\text { R\$ }\end{array}$ \\
\hline BN & 2 & $10+$ & Baixa & Alto & 20 & $30,00-10,00$ \\
\hline CM & 1 & $5+$ & Alta & Muito alto & 5 & $5,00-19,00$ \\
\hline DAM & 2 & $6+$ & Médio & Médio & 10 & $4,00-460,00$ \\
\hline DOM & $2-4$ & $6+$ & Médio & Médio & 10 & $3,00-230,00$ \\
\hline RU & 1 & $6+$ & Alta & Alto & 10 & $7,00-200,00$ \\
\hline SUD & 1 & $6+$ & Baixa & Baixo & 5 & $4,00-60,00$ \\
\hline T/M & 2 & $6+$ & Médio & Alto & 15 & $7,00-90,00$ \\
\hline XAD & 2 & $5+$ & Alta & Muito alto & 15 & $20,00-1.260,00$ \\
\hline
\end{tabular}

Na Tabela 2, são apresentadas as principais habilidades trabalhadas em cada um destes jogos.

Tabela 2. Habilidades trabalhadas por cada jogo.

\begin{tabular}{|c|c|}
\hline Jogos & Habilidades Trabalhadas \\
\hline BN & Estratégia e noção espacial \\
\hline CM & Concentração, memorização e estratégia \\
\hline DAM & Estratégia \\
\hline DOM & Concentração, estratégia e pensamento matemático \\
\hline RU & $\begin{array}{r}\text { Raciocínio matemático, estratégia, concentração, } \\
\text { antecipação e coordenação motora. }\end{array}$ \\
\hline SUD & $\begin{array}{r}\text { Memorização, atenção seletiva e alternada, } \\
\text { concentração e estratégia }\end{array}$ \\
\hline T/M & Estratégia e percepção espacial \\
\hline XAD & Estratégia e tática \\
\hline
\end{tabular}


Estes jogos indicam que pessoas a partir dos 5 anos de idade conseguem participar ativamente, desde níveis de complexidade baixa (Sudoku) até alta (Xadrez e Cubo Mágico). A duração das partidas destes jogos é relativamente rápida (entre 5 a 20 minutos). Acredita-se que é mais interessante trabalhar com crianças os jogos que participam 2 ou mais jogadores para estimular a interação social entre eles. Para adolescentes/adultos, o uso de jogos individuais espera ser mais efetivo, pois trabalha a dedução de futuras ações (tanto sua quanto do oponente). Sabe-se, também, que algumas pessoas ficam frustradas quando não conseguem terminar um jogo como, por exemplo, o Cubo Mágico. Neste caso, é fundamental ter o suporte de professores, ensinando métodos ou caminhos da solução. Ao compreender as regras associadas a cada jogo, é natural que se tenha mais vontade de aprender e, com isso, raciocinar melhor cada ação a ser executada. Em relação aos preços dos jogos, há uma diferença significativa entre o menor e o maior valor encontrado, mas isso se deve ao tipo de material envolvido na fabricação das peças.

Em seguida, foram acessados os sites de Internet citados na seção 1, que disponibilizam estes jogos a fim de constatar cada uma das características apontadas anteriormente. Pôde-se observar que os jogos dispõem de interfaces descontraídas, algumas semelhantes ao jogo físico e outras, como o jogo Batalha Naval, em que compõe-se de temas e mídias audiovisuais que chamam bastante atenção do jogador. Ademais, alguns dos sites analisados permitem que os usuários acompanhem de forma gradual os níveis de conhecimento de todos os jogadores, fomentando a competitividade entre eles. Com isso, o jogador pode identificar o seu nível de raciocínio lógico. Para os jogos Batalha Naval, Damas, Dominó, Trilha/Moinho e Resta Um, a semelhança é bastante significativa do ponto de vista das habilidades e da forma de jogar entre as duas versões. Outro ponto a ser considerado é a possibilidade de o computador atuar como um jogador, não necessitando da disponibilidade de jogadores humanos. Neste caso, isto é mais facilmente encontrado nos jogos de Damas, Xadrez, Batalha Naval e Dominó.

O jogo Cubo Mágico, por sua vez, que possui níveis de complexidade e de estratégia altos, presumivelmente torna-se mais maçante e complexo quando trabalhado na versão digital pelo fato de não ser possível o manuseio do cubo em si, embora haja a presença de sons e recursos visuais. De modo geral, ambas versões dos jogos citados dão suporte para o desenvolvimento do raciocínio lógico e das habilidades elencadas, no entanto os jogos no formato de tabuleiro tendem a ser mais expressivos devido possibilitar uma interação social presencial, característica essencial nos dias atuais.

\section{Considerações Finais}

Durante muitos anos os jogos digitais tiveram ascensão devido à evolução da tecnologia, no entanto, os jogos de tabuleiro estão sendo cada vez mais requisitados para aumentar a interação social entre pessoas. Ressalta-se que, independente da sua versão (digital ou físico), os jogos têm um papel significativo no desenvolvimento de habilidades importantes, principalmente, para pessoas que estão em processo de formação cognitiva.

Nesta pesquisa, os jogos escolhidos estimulam habilidades para despertar o raciocínio lógico e acredita-se ser muito interessantes para crianças a partir dos 5 anos de idade. Através do jogo, as pessoas podem pensar, levantar hipóteses, antecipar, planejar, interpretar e criar estratégias, permitindo que o aprendizado ocorra de modo alternativo, pois a resolução de um problema é um momento em que a criança ou adolescente tem a possibilidade de buscar um caminho próprio que, segundo ele, seja mais significativo. Para os jogos que têm complexidade e nível estratégicos altos, uma alternativa é a ajuda de um adulto ou professor que tenha experiência e que dê caminhos para a criança buscar a solução. Assim, o uso de jogos em 
instituições de ensino é de extrema relevância, pois além do caráter lúdico e divertido que proporciona ao jogador, também desenvolve funções que vão além do entretenimento, envolvendo aspectos sociais, cognitivos e afetivos do aluno.

Sobre o tipo de versão destes jogos, observou-se que os digitais são mais acessíveis pelo fato de necessitar apenas de conexão com Internet, não dispor de espaço físico para poder jogar, possibilidade de jogar com o computador e recursos mais ricos e dinâmicos de interface. Já em termos da versão em tabuleiro, vale a pena ressaltar que, de modo geral, estes apresentam baixo custo (Sudoku, Resta Um e Dominó são os mais baratos) e desenvolvem habilidades importantes para as pessoas em fase escolar, sobretudo, interação social entre alunos. Esperase que os resultados apresentados neste trabalho sirvam de direcionamento para a escolha de quais jogos utilizar conhecendo suas características básicas, bem como as habilidades que podem ser desenvolvidas.

Através das informações obtidas com este trabalho, pretende-se levar à campo, onde será aplicado com alunos de acordo com a faixa etária inicial (apresentada na Tabela 1) a fim de poder experienciar em prática e obter resultados mais precisos em consideração aos níveis de complexidade, estratégia e tempo. Utilizando tanto a versão tabuleiro quanto digital. Os professores e alunos podem explorar mais os jogos, em suas possíveis versões, e a sua função no desenvolver da lógica. Permitindo que o professor reflita a respeito de sua própria prática didática, presumir novas ações de ensino que deseja desenvolver com os alunos, e sobre as maneiras em que os alunos progridem, instigando os mesmos e despertando suas curiosidades.

\section{Referências Bibliográficas}

Balasubramanian, N. and Wilson, B. G. Games and Simulations. Society for information technology and teacher education International conference. (2006). Disponível em: http://www.coulthard.com/library/Files/balasubramanianwilson_2005-gamesandsimulations.pdf. Acesso em: 18 de abril de 2019.

Banks-Leite, L. (1996) "Aspectos argumentativos e polifônicos da linguagem da criança em idade pré-escolar". Tese de Doutorado. IEL/Unicamp, Campinas, http://www.bibliotecadigital.unicamp.br/document/?code=vtls000102752, setembro/2016.

Copi, Irving M. (1978), Introdução à Lógica. São Paulo: Mestre Jou, $2^{\mathrm{a}}$ ed.

dos Santos, W. O., da Silva, A. P., and da Silva Junior, C. G. (2014). Conquistando com o resto: Virtualização de um jogo para o ensino de matemática. In Brazilian Symposium on Computers in Education (Simpósio Brasileiro de Informática na Educação-SBIE), volume 25, p. 317-321.

Geller, Marlise; Silveira, Sidnei Renato. Estudo e Análise de Jogos Educativos Computadorizados. Relatório de Pesquisa. Canoas: ULBRA, 1998.

Gros, Begoña. The impact of digital games in education. First Monday, v.8, n. 7, jul. 2003. Disponível em: <http://www.firstmonday.org/issues/issue8_7/xyzgros/index.html>. Acesso em: 18 abril de 2019.

Oliveira, W. \& A. de S., A. \& K. T. da Silva, A. \& L. S. de Oliveira, M. \& R., S. \& R., A \& Gomes da Silva Junior, C. (2015). Development Process of an Educational Game: An experience in Brazil. XIV Brazilian Symposium on Computer Games and Digital Entertainment. 200.

Piaget, J. 1975, Gênese das estruturas lógicas elementares. Rio de Janeiro: Forense. 
Rauber, J., Rosseto, M., Fávero, A. M., Fávero, A. A., Tonieto, C. 2003. Que tal um pouco de lógica?!. Ed. Clio Livros, Passo Fundo.

Santos, W. and Silva Junior, C. (2016). Challenges of games virtualization applied to educational games. In V Workshop of Challenges of Computers in Education, pages 597606.

Sérates, J. O homem lógico. Revista Isto é, set. 1998. 